\title{
A inserção de Computação como disciplina no Ensino Fundamental: Desafios e Conquistas em Estágio Supervisionado
}

\author{
Arianne Sarmento Torcate, Marcos Uryel F. de Farias, Sônia Regina Fortes da \\ Silva, Cleiton Soares Martins \\ Universidade de Pernambuco, Campus Garanhuns (UPE) \\ CEP 55.294-902 - Garanhuns - PE - Brasil \\ \{ariannesarmento0, uryel.farias, fortes.sonia\}@gmail.com, \\ cleiton.martins@upe.br
}

\begin{abstract}
The present article analyzes the teaching experience in undergraduate degree in Computing of the University of Pernambuco (UPE) - Campus Garanhuns, in the final years of elementary education, in the teaching of the discipline of Educational Computing. The purpose was to implement an educational training with young people, applying the axes: computational thinking, the world and digital culture, articulating this knowledge with students of the 6th grade B, Elementary School, School of Application Professor Ivonita Alves Guerra in Garanhuns / PE, using as a means of learning leisure activities and software. It was verified that the pedagogical action promoted a greater understanding of the students on the proposed contents.
\end{abstract}

Resumo. O presente artigo analisa a experiência docente em curso de Licenciatura em Computação da Universidade de Pernambuco (UPE) Campus Garanhuns, nos anos finais do ensino fundamental, no ensino da disciplina de Computação Educacional. A finalidade foi implementar uma formação educativa com jovens, aplicando os eixos: pensamento computacional, mundo e cultura digital, articulando este conhecimento com educandos do $6^{\circ}$ ano B, do Ensino Fundamental, da Escola de Aplicação Professora Ivonita Alves Guerra em Garanhuns/PE, utilizando como meio de aprendizagem atividades e softwares lúdicos. Constatou-se que a ação pedagógica promoveu um maior entendimento dos educandos sobre os conteúdos propostos. 


\section{Introdução}

As pessoas e as sociedades em que vivem testemunham mudanças de conceitos, valores e tecnologias constantemente. Devido ao ciclo natural do homem em procurar descobrir e aprender coisas novas, viver em sociedade requer apropriar-se de conhecimentos e habilidades específicas dependendo de suas necessidades e do contexto em que está inserido. Nessa perspectiva, diversos países estão buscando o acesso ao conhecimento com o uso de novas tecnologias, deste modo esta oferta tem sido muitas vezes experimentada por meio da informatização das escolas.

É notável o interesse e o progresso em relação às Tecnologias da Informação e Comunicação (TIC), que vários países estão tendo ultimamente, emergindo desse contexto iniciativas que buscam introduzir tecnologias no processo educativo e adaptando o uso da Computação, enquanto ciência, ao currículo escolar. Mas sabendo que a Computação não está inserida na base comum curricular brasileira, esta realidade acaba por retardar o processo de desenvolvimento tanto do país como também não prepara o estudante para um mercado de trabalho vasto e que está em pleno processo de ascensão.

Para todos os profissionais ainda em formação, o estágio é um dos momentos mais importantes e significativos, e quando se trata de um estágio na área de licenciatura, é nesse momento que o futuro profissional tem oportunidade de entrar em contato direto com a realidade profissional no qual será inserido, além de concretizar pressupostos teóricos adquiridos pela observação de determinadas práticas específicas e do diálogo com profissionais mais experientes, assim obtendo a troca de experiências.

No curso de Licenciatura em Computação da Universidade de Pernambuco (UPE) - campus Garanhuns, seu discente deve estar preparado para a realidade atual do Brasil em relação a sua área de atuação, assim como estar apto a ingressar em seu âmbito profissional no papel de professor. E para isto, o componente curricular Estágio Supervisionado II tem como função de preparar o futuro docente a atuar no âmbito escolar, especificamente no Ensino Fundamental, que neste caso o projeto de ensino deste componente curricular foi realizado na Escola de Aplicação Professora Ivonita Alves Guerra, localizada na cidade de Garanhuns/PE.

O projeto da dimensão de Ensino é baseado a partir do Programa de Componente Curricular elaborado pelos professores supervisores do Estágio Supervisionado II, que tem como objetivo inserir os futuros docentes no âmbito escolar, onde foram encarregados de ministrar o componente curricular denominado Computação Educacional, contemplando a turma do $6^{\circ}$ ano $\mathrm{B}$ durante o segundo semestre de 2017, a fim de desenvolver o Pensamento Computacional dos educandos, contextualizando com o mundo e Cultura Digital da sociedade ao qual estão imersos. 
Este artigo está organizado em 6 seções. Além da introdução, a seção 2 descreve alguns trabalhos que estão relacionados à nossa proposta de Ensino, na seção 3 é dado o início ao relato com informações gerais sobre o projeto, seguido de uma subseção detalhando as experiências vivenciadas. A seção 4 destaca quais foram os desafios que surgiram ao longo do projeto, como também o que se pôde aprender a partir deles. $\mathrm{Na}$ seção 5 mostra claramente os efeitos do trabalho realizado, assim como os resultados apresentados pelos educandos envolvidos na disciplina Computação Educacional e na seção 6 são relatadas as opiniões críticas dos autores deste artigo quanto a toda execução do projeto de Ensino e das experiências que foram vivenciadas.

\section{Trabalhos Relacionados}

Os trabalhos citados nesta seção estão diretamente ligados com o contexto do presente artigo, onde são expostas reflexões sobre à inserção do Ensino de Computação e as experiências vivenciadas ao promover esse ensino, seja ele de forma interdisciplinar ou não. É de grande valia esse momento de leitura de trabalhos que já foram executados, pois é através deles que podemos melhorar e adaptar nosso projeto, tornando-o mais robusto e coeso.

Em Silva et al. (2017), os autores relatam a experiência vivenciada através da disciplina de Estágio Curricular V do curso de Licenciatura em Computação da Universidade Federal Rural de Pernambuco, onde foi proporcionado a professores de escolas públicas um curso de formação de professores em Pensamento Computacional, com o intuito de promover Computação como Ciência interdisciplinar. É válido mencionar que os autores observaram uma desmotivação partindo de alguns dos professores convocados para participação do curso por não terem conhecimento sobre a temática do projeto e os que participaram se surpreenderam ao descobrir a relação do tema com a tecnologia.

Em Reis et al. (2017), os autores apresentam e descrevem como se deu a experiência do ensino de conceitos de Ciências da Computação aplicada no ensino fundamental, sempre relacionando com o Pensamento Computacional e buscando formas de ensino que proporcionem uma aprendizagem significativa para os alunos. Para que isso fosse possível, os autores utilizaram metodologias diferenciadas, como: Storytelling, Computação Desplugada e Gamificação, com o intuito de despertar nos alunos habilidades que estão diretamente associadas ao Pensamento Computacional.

No trabalho de Torcate et al. (2017), os autores relatam a experiência do Ensino de Computação de forma interdisciplinar com Português, onde foram abordados conceitos fundamentais de Computação, exemplo: Números Binários, Pensamento Computacional e Estrutura Condicional. $\mathrm{O}$ referido artigo traz resultados relevantes, como o desenvolvimento de um Objeto de Aprendizagem criado em cima das dificuldades e necessidades dos alunos, foram também utilizados softwares para auxiliar os alunos na criação de histórias em quadrinhos, como por exemplo o HagáQuê. 
Em França et al. (2012) são apresentadas as experiências adquiridas no ensino de Computação numa escola pública do Estado de Pernambuco, onde utilizou-se como metodologia de ensino a Computação Unplugged e o Scratch. No decorrer do trabalho referido, os autores detalham em como se deu a execução do projeto, no que se refere à avaliação, os alunos foram acompanhados continuamente, onde era observado o comportamento e o desempenho dos mesmos e a cada fim de aula era aplicado um questionário para obter informações relevantes, como por exemplo as dificuldades encontradas e a verificação do nível de absorção dos conteúdos abordados.

Silva et al. (2015) traz a discussão política e desperta a reflexão da inserção do ensino de Computação na educação básica juntamente com o relato de experiência de estagiários do curso de Licenciatura em Computação, o projeto foi realizado em três escolas públicas no ensino fundamental, onde foi proposto o desenvolvimento de jogos 2D utilizando a ferramenta Game Maker e o ensino de conceitos básicos de Ciências da Computação.

Diante das fundamentações teóricas abordadas, é notável os desafios que foram e ainda são enfrentados para a inclusão do Ensino de Computação no âmbito escolar, mas é evidente os benefícios que são proporcionados e as contribuições que a Computação tem para a educação e todas as suas áreas de conhecimento. Portanto, tendo em vista esse contexto, a Computação e seus respectivos conteúdos têm proporcionado momentos relevantes e diferenciados, trazendo a dimensão tecnológica para sala de aula, quebrando paradigmas e proporcionando o ensino e a aprendizagem significativa com o auxílio de softwares e ferramentas lúdicas.

\section{Relato de Experiência}

Como foi dito brevemente na primeira seção deste artigo, está seção tem como objetivo detalhar a experiência do estágio docente, que ocorreu no segundo semestre de 2017 na Escola de Aplicação, na turma do $6^{\circ}$ ano B com participação de 12 alunos, na qual foram ministradas aulas da disciplina Computação Educacional, pelos discentes autores deste artigo, aulas estas que ocorriam duas vezes por semana, uma aula na segunda e outra na quarta com duração de uma hora e todas elas contando com a supervisão de pelo menos um dos professores de Estágio Supervisionado.

O início das atividades de estágio se deu pela elaboração de um planejamento baseado a partir de um documento denominado Programa de Componente Curricular, criado pelos próprios professores supervisores de estágio, documento este que serviu como referência para elaboração e execução das aulas de Computação Educacional.

Os conteúdos programados podem ser vistos a seguir na Tabela 1, onde estão subdivididos em três seções, que por meio da atuação dos discentes como professores, tem como objetivo construir e desenvolver competências e habilidades nos educandos a 
partir dos conteúdos apresentados, fazendo isso de forma ativa através do desenvolvimento prático e teórico da disciplina.

Tabela 1. Conteúdo de Computação Educacional.

\section{Conteúdo programático}

\section{1- Pensamento Computacional e Algoritmos}

1.2 - Algoritmo utilizando linguagens visuais e de programação.

1.3 - Trabalhar a construção de soluções de problemas.

\section{2 - Ecossistemas Digitais}

2.1 - Tratar a Relação entre os Hardwares, Softwares e as camadas dos Sistemas Operacionais.

2.2 - Estrutura e funcionamento da internet.

\section{3 - Culturas Digitais}

3.1 - Utilização das tecnologias no contexto escolar, social e profissional trazendo seu risco, responsabilidade e impactos quando são utilizados.

3.2 - Manipulação de dados e seus softwares.

3.3 - Lógica de ordenamento de resultados e sua utilização para novas aprendizagens.

Inicialmente o conteúdo proposto pode parecer algo complexo, visto que dificilmente algum aluno estudou algo referente à Computação dentro da escola, em virtude disso, grande parte dos conteúdos desenvolvidos no planejamento da disciplina foram trabalhados de forma lúdica, por meio de atividades desplugadas, ou seja, um tipo de atividade oriunda da Computação, onde não há necessidade do uso de um computador para sua execução.

Também foram adotadas algumas outras práticas como o uso das tecnologias educativas a serem utilizadas pelos educandos de forma individual ou em equipe, como por exemplo: jogos educacionais, dinâmicas em sala de aula e atividades na Web. É válido destacar que a escola sede do projeto possui um laboratório ativo, o que possibilitou as aulas práticas laboratório.

\subsection{Execução do Projeto}

Em prol de tornar as aulas da disciplina algo notável e atraente ao olhar dos educandos, foi tido como objetivo se distanciar ao máximo da metodologia tradicional de ensino, onde o professor transmite informação e os educandos passivamente apenas absorvem essas informações. Desta forma, durante todas as aulas da disciplina os educandos eram sempre estimulados a participarem ativamente das aulas, seja por meio de um diálogo sobre algum conteúdo da aula, solucionar uma atividade no quadro e até mesmo dar a liberdade para eles relatarem alguma ideia, opinião ou questionamento que vinhesse a surgir durante as aulas. 
Foram utilizadas juntamente com as aulas teóricas atividades práticas com o intuito de fixar o conteúdo proposto, sendo elas desplugadas, adaptadas para despertar nos alunos o raciocínio lógico. Sabendo disso, algumas das atividades desplugadas tendo como base o livro de Tim Bell et al (2011), foram: Cidade Enlameada, Happy Maps e Pintando números binários. Já para as atividades adaptadas, foram utilizadas: Estrela mágica e Reconhecendo os valores. Quanto às aulas práticas no laboratório, foram utilizadas os seguintes portais: Code.org, Blockly Games e Lightbot.

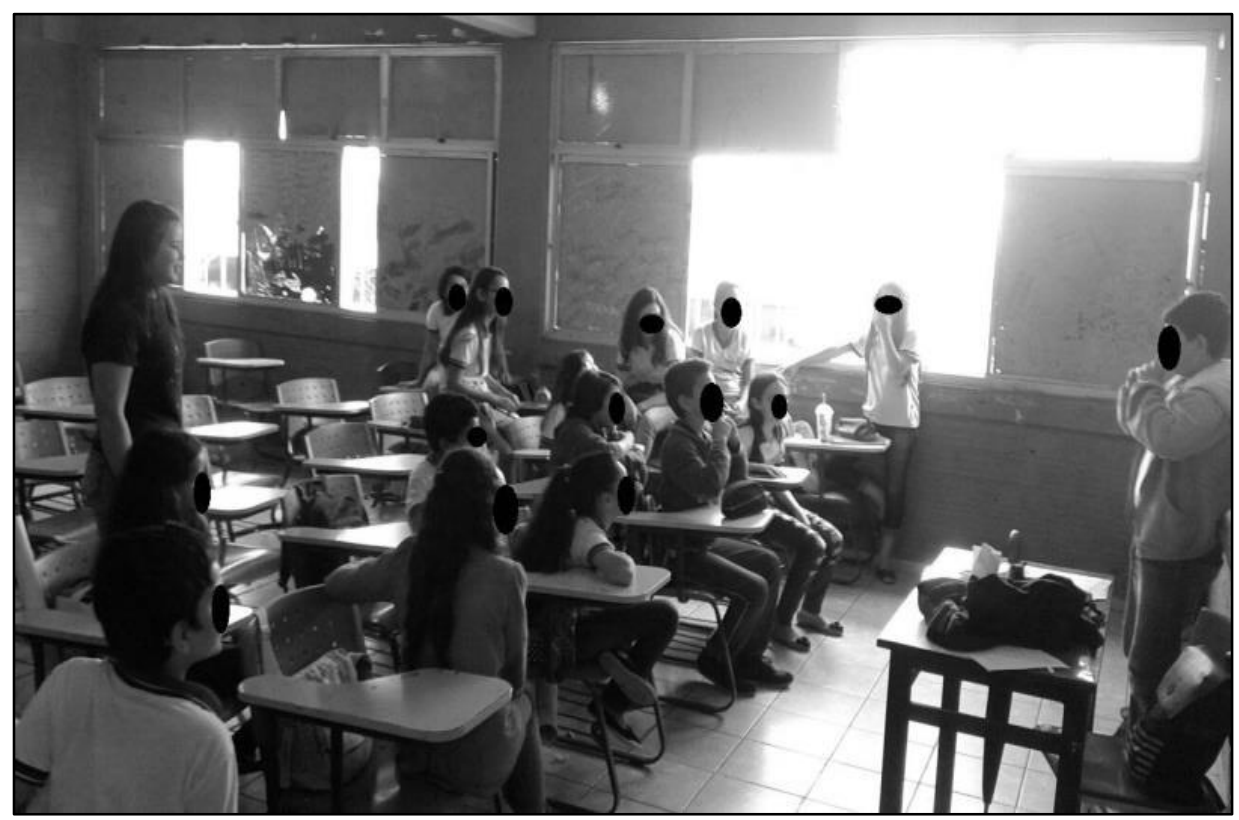

Figura 1. Educandos participando da atividade desplugada.

Nas aulas teóricas com atividades desplugadas representada pela Figura 1, foi percebido o real interesse dos educandos, visto que o engajamento deles nessas atividades era algo notável, pois eles sempre demonstravam curiosidade para saber que tipo de atividade nova seria aplicada em sala de aula, tudo isso foi relatado pelos próprios educandos, como pode ser visto pelas palavras de alguns deles "como é bom fazer esse tipo atividade, é bem mais legal aprender assim".

Já nas aulas práticas, onde os educandos eram levados ao laboratório de informática da escola, o interesse deles aumentava ainda mais, e com softwares e sites educacionais de programação já citados, foi possível disseminar o Pensamento Computacional e a construção de algoritmos por meio de jogos de programação lúdicos que contém uma linguagem de programação visual e de fácil interpretação e aprendizagem, como é demonstrado na Figura 2, onde o aluno apresenta um algoritmo para solução de um problema na plataforma de programação Blockly Games. 


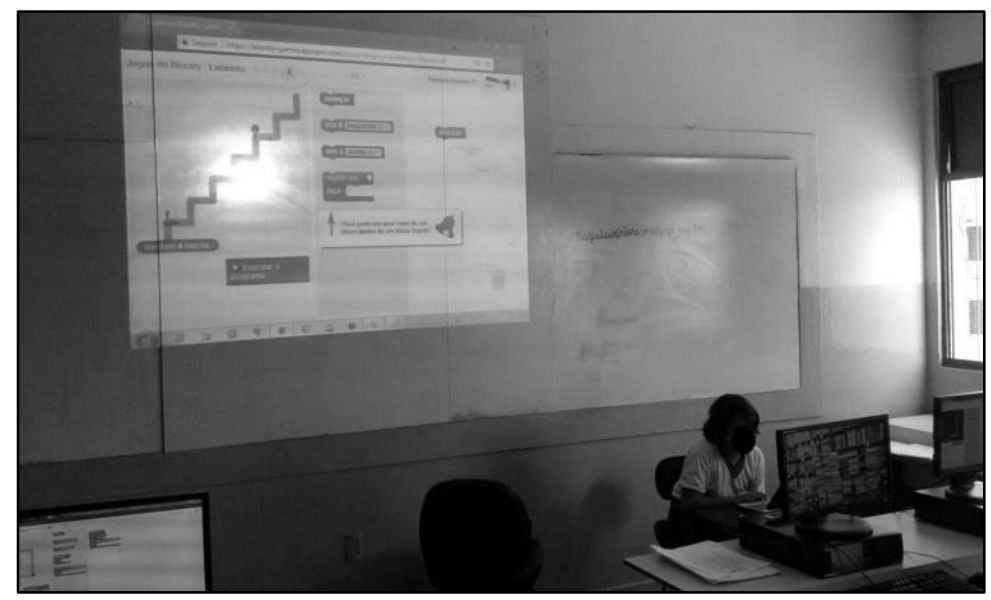

Figura 2. Educando apresentando seu algoritmo no Blockly Games.

Com a finalidade de dinamizar e sair um pouco da rotina, também foi pensado em uma dinâmica para simular em como as informações passam pelos componentes do computador até chegar realmente ao usuário, para isso foi formada uma fila com os alunos, onde o último da fila passava a informação para o próximo até chegar ao primeiro da fila, essa dinâmica foi utilizada a fim de demonstrar e contextualizar com os educandos em o quanto as informações são mudadas e adaptadas até chegar aos usuários.

Sendo assim, vale reforçar que todas essas estratégias foram utilizadas com o intuito maior de quebrar os paradigmas tradicionais, onde o professor é visto como o único "dono do saber", sendo assim, andamos lado a lado com os alunos, construindo um conhecimento mais significativo e mostrando que isso é possível através de diálogos e troca de informações, que consequentemente torna o processo de ensino e aprendizagem uma experiência rica e de qualidade em termos de Educação.

\section{Limitações e Lições aprendidas}

Tendo em vista toda trajetória vivenciada pelos autores deste artigo, é válido relatar que como esta foi uma experiência nova e desafiadora, tivemos nossas limitações que consequentemente ocasionaram no atraso do nosso projeto e também no adiantamento de alguns assuntos, atraso este que se deu por praticamente a ausência de aulas no mês de Outubro nas Segundas e Quartas.

Sabendo disto, é válido ressaltar que no mesmo dia que eram ministradas aulas no sexto ano A, também havia aula para o sexto ano B da mesma disciplina, mas com outros estagiários, sendo assim, em relação às aulas práticas, tivemos que revezar o uso do laboratório para que todos pudessem ter acesso aos computadores e as ferramentas online, já que só tem um laboratório na escola.

Enquanto profissionais ainda em formação, pode-se dizer com propriedade que todos os imprevistos que ocorreram durante a execução do projeto contribuíram fortemente para melhoria da metodologia dos estagiários, onde foi possível rever 
também a didática e criar a habilidade de adaptar as atividades de acordo com a realidade dos alunos e sempre possuir um plano $b$, tornando assim o planejamento mais flexível e menos propício à situações que venham a prejudicar o projeto.

\section{Resultados}

Os resultados adquiridos foram notáveis, através do acompanhamento contínuo dos educandos, isso foi possível através da participação, desempenho e coerência ao responder as atividades propostas, também foram aplicadas duas atividades avaliativas que foram realizadas individualmente com base nos conceitos de Computação trabalhados durante as aulas, como por exemplo: Pensamento Computacional, Redes de Computadores, Sistemas Operacionais, Criptografia e Números Binários.

Tendo como base os resultados das duas atividades avaliativas, foi possível notar a evolução significativa dos educandos por meio de uma análise minuciosa das notas da atividade avaliativa I, em que a média total da turma foi de 6,8 e na atividade avaliativa II onde a média total aumentou para 9,0. Diante desse resultado, pôde-se concluir que houve um desempenho gradativo dos educandos durante o decorrer da disciplina, que é visivelmente notável através da comparação entre as médias das atividades avaliativas.

Além disso, durante as aulas provocamos a curiosidade dos alunos em relação a alguns assuntos, como: Linguagens de programação e Sistemas Operacionais, a fim de utilizar a curiosidade dos mesmos como uma estratégia para estimular seu interesse e solicitar pesquisas, assim fazendo com que o educando buscasse informações e trouxessem para sala, com o intuito de socializar o conhecimento adquirido com os colegas.

Também foi possível ver o pensamento crítico dos educandos quanto às tecnologias que agora estão tão inseridas na cultura do país e do mundo, por meio das aulas sobre Cultura Digital, nas quais eram debatidos temas como: $\mathrm{O}$ modo como às tecnologias influenciam no nosso modo de viver e de se comunicar, como ela pode e é usada no âmbito escolar, considerando suas vantagens e desvantagens. Os educandos conseguiram argumentar de forma bem interessante e construtiva nestas aulas, expondo suas opiniões e debatendo sobre os temas propostos, de fato foram momentos bastante prazerosos de serem vivenciados em sala de aula.

Diante de alguns depoimentos dados pelos professores/supervisores do Estágio Supervisionado II e da direção da escola, vale ser mencionado também o espaço que conquistamos e em como passamos a ser vistos pelas pessoas que compõem o âmbito escolar no qual estávamos inseridos, isso foi notável através do reconhecimento do trabalho que foi realizado e compromisso com os educandos que foi assumido desde o início do projeto de Ensino. 


\section{Considerações Finais}

Durante esse período de estágio, pode-se perceber a evolução profissional dos estagiários que puderam atuar como professores titulares da disciplina de Computação Educacional.

O projeto que foi executado pode claramente ser considerado uma grande conquista, pois é do conhecimento de todos que ainda não há na grade curricular a Computação como disciplina nas escolas, e sabe-se de todas as lutas para que isso se firme e o quanto o caminho é longo para que a Computação seja inserida realmente como uma disciplina, sendo assim, o Estágio Supervisionado nos proporcionou essa vivência que tornou-se essencial para nossa formação.

Diante do trabalho que foi desenvolvido e relatado neste artigo, pode-se notar a necessidade e os benefícios da inclusão da Computação no âmbito escolar, isso foi perceptível através das competências e habilidades que foram despertadas nos educandos. Tendo em vista que a tecnologia já faz parte do cotidiano dos alunos, é importante mostrar que a mesma não só serve para momentos de lazer, mas se usada de forma correta torna-se uma grande ferramenta auxiliadora no processo de ensino e aprendizagem.

\section{Referências}

Bell, T.; Witten, I. e Fellows, M. (2011). “Computer Science Unplugged - Ensinando Ciência da Computação sem o uso do Computador". Tradução de Luciano Porto Barreto, 2011. Disponível em: <http://csunplugged.org/>. Acesso em: 26 de agosto 2017.

França, R. T., Silva, W. C., Amaral, H. J. C. (2012). "Ensino de Ciência da Computação na Educação Básica: Experiências, Desafios e Possibilidades”. XX Workshop sobre Educação em Computação (WEI).

Reis, F. M., Oliveira, F. C. S., Martins, D. J. S., Moreira, P. R. (2017). "Pensamento Computacional: Uma Proposta de Ensino com Estratégias Diversificadas para Crianças do Ensino Fundamental”. XXIII Workshop de Informática na Escola (WIE 2017).

Silva, S. F., Barbosa, A. F., Souza, A. A., Silva, E. G., Oliveira, M. L. S., Neto, S. R. S., and do Santos, O. W. (2015). "Relato de Experiência de Ensino de Computação no Ensino Fundamental em Estágio Supervisionado da Universidade de Pernambuco no Campus Garanhuns”. Workshop sobre Educação em Computação.

Silva, V., Silva, K., França, R. T. (2017). "Pensamento computacional na formação de professores: experiências e desafios encontrados no ensino da computação em escolas públicas”. XXIII Workshop de Informática na Escola (WIE 2017). 
Sociedade Brasileira de Computação. "Referenciais de Formação em Computação: Educação Básica”, 16 de agosto de 2017. Disponível em: $<$ http://www.sbc.org.br/noticias/10-slideshow-noticias/1996-referenciais-deformacao-em-computacao-educacao-basica>. Acesso em: 25 de agosto de 2017.

Torcate, A. S., Farias, M. U. F., Santos, H. R. M. (2017). "Relato de Experiência do PIBID: Promovendo o Ensino de Computação de forma interdisciplinar com Português no Ensino Fundamental". XXIII Workshop de Informática na Escola (WIE 2017). 